\title{
Topside equatorial zonal ion velocities measured by C/NOFS during rising solar activity
}

\author{
W. R. Coley, R. A. Stoneback, R. A. Heelis, and M. R. Hairston \\ W. B. Hanson Center for Space Sciences, University of Texas at Dallas, Richardson, TX, USA \\ Correspondence to: W. R. Coley (coley@utdallas.edu)
}

Received: 17 October 2013 - Accepted: 20 December 2013 - Published: 4 February 2014

\begin{abstract}
The Ion Velocity Meter (IVM), a part of the Coupled Ion Neutral Dynamic Investigation (CINDI) instrument package on the Communication/Navigation Outage Forecast System (C/NOFS) spacecraft, has made over $5 \mathrm{yr}$ of in situ measurements of plasma temperatures, composition, densities, and velocities in the $400-850 \mathrm{~km}$ altitude range of the equatorial ionosphere. These measured ion velocities are then transformed into a coordinate system with components parallel and perpendicular to the geomagnetic field allowing us to examine the zonal (horizontal and perpendicular to the geomagnetic field) component of plasma motion over the 2009-2012 interval. The general pattern of local time variation of the equatorial zonal ion velocity is well established as westward during the day and eastward during the night, with the larger nighttime velocities leading to a net ionospheric superrotation. Since the C/NOFS launch in April $2008, F 10.7 \mathrm{~cm}$ radio fluxes have gradually increased from around 70 sfu to levels in the 130-150 sfu range. The comprehensive coverage of C/NOFS over the low-latitude ionosphere allows us to examine variations of the topside zonal ion velocity over a wide level of solar activity as well as the dependence of the zonal velocity on apex altitude (magnetic latitude), longitude, and solar local time. It was found that the zonal ion drifts show longitude dependence with the largest net eastward values in the American sector. The pre-midnight zonal drifts show definite solar activity (F10.7) dependence. The daytime drifts have a lower dependence on F10.7. The apex altitude (magnetic latitude) variations indicate a more westerly flow at higher altitudes. There is often a net topside subrotation at low F10.7 levels, perhaps indicative of a suppressed $\mathrm{F}$ region dynamo due to low field line-integrated conductivity and a low $\mathrm{F}$ region altitude at solar minimum.
\end{abstract}

Keywords. Ionosphere (equatorial ionosphere; ionosphereatmosphere interactions; plasma convection)

\section{Introduction}

The study of $\mathrm{F}$ region plasma drifts and neutral winds is important to an understanding of the dynamics and thermal balance of the thermosphere and ionosphere. Early observations of zonal and vertical plasma flow at low latitudes were largely limited to those provided by ground-based techniques such as the Jicamarca incoherent scatter radar in Peru (e.g., Woodman, 1972; Fejer et al., 1979a, b, 1981, 1985, 1991). Such measurements provide comprehensive coverage with respect to local time, seasonal, and solar activity dependences at one geographic location. In situ satellite-based observations from spacecraft such as Atmosphere Explorer, Dynamics Explorer 2, San Marco, DMSP, ROCSAT-1, and C/NOFS (e.g., Maynard et al., 1988, 1995; Coley and Heelis, 1989; Coley et al., 1994; Hartman and Heelis, 2007; Huang et al., 2010; Fejer et al., 2013) have been used to examine ionospheric drifts (or equivalently electric fields) over spatially more extensive regions, with the limitation of mixing local time, latitude, and longitude. The electric fields measured, in turn, are the result of a complicated electrodynamic interaction between the $\mathrm{E}$ and $\mathrm{F}$ regions that varies greatly from day to night. Neutral tidal winds create the E region dynamo field that maps along equipotential field lines to the $\mathrm{F}$ region. The $\mathrm{F}$ region dynamo field is largely shorted through the $\mathrm{E}$ region during the day but becomes more important in the evening as the $\mathrm{E}$ region conductivity declines (e.g., Heelis et al., 1974; Heelis, 2004). The basic characteristics of zonal plasma drift at the equator have been presented by Fejer et al. (1981, 1985) and Fejer (2011) using Jicamarca data. A typical diurnal cycle consists of westward drifts of about $50 \mathrm{~m} \mathrm{~s}^{-1}$ during the day that are solar cycle independent and solar-cycle-dependent nighttime eastward drifts that peak pre-midnight with an average value 
of around $130 \mathrm{~m} \mathrm{~s}^{-1}$. Near the F peak when the zonal flow is averaged over all local times, a net superrotation is normally observed. The daytime east-west $\mathrm{F}$ region drifts are representative of the $\mathrm{E}$ region neutral winds that generate the vertical electric fields in the equatorial $\mathrm{F}$ region (Woodman, 1972). At night the coupling between the $\mathrm{E}$ and $\mathrm{F}$ regions decreases, and the nighttime zonal drifts become more nearly equal to the $\mathrm{F}$ region neutral winds that generate these fields (Woodman, 1972; Heelis et al., 1974). The local time variation of the east-west drifts has been examined by Maynard et al. (1988), Coley and Heelis (1989), and Coley et al. (1994) using DE 2 satellite measurements of the electric field during a high solar flux period. Near solar maximum Pacheco et al. (2011) looked at magnetic latitude variations of zonal drifts using measurements from the ROCSAT- 1 spacecraft. Recently, Pfaff et al. (2010) have shown the first results for a limited period of 2008 of $F$ region zonal and vertical drift from the Vector Electric Field Instrument (VEFI) instrument on board the Communication/Navigation Outage Forecast System (C/NOFS) spacecraft. Fejer et al. (2013) also present VEFI results but for the more extended period of 2008-2011 observing longitudinal structure and wave- 4 signature in the electric field.

The Coupled Ion Neutral Dynamic Investigation (CINDI) is an experiment on board the C/NOFS spacecraft that was launched into orbit on 16 April 2008. C/NOFS is in an ideal position to study the general behavior of the equatorial topside ionosphere as a function of solar activity. Early C/NOFS climatology results using CINDI indicate that the ionosphere is extremely cold $(\sim 600 \mathrm{~K})$ at night, and the $\mathrm{O}^{+}$to $\mathrm{H}^{+}$transition height was extremely low during the 2008 solar minimum and has latitudinal and LT variations (Heelis et al., 2009; Coley et al., 2010). The launch of C/NOFS coincided with the deepest solar minimum since the space age began with extended periods of no sunspots and $\mathrm{F} 10.7 \mathrm{~cm}$ radio fluxes in the 60-70 sfu range. This low solar activity continued until near the end of 2009 when there was a recurrence of low-level sunspot activity that gradually increased through 2012. In this paper we present the observed variations of the topside zonal plasma velocity as measured by CINDI for the 2009-2012 time period as a function of solar activity, longitude and solar local time (SLT).

\section{Spacecraft instrumentation, orbit, and data}

The Ion Velocity Meter (IVM) is the part of the CINDI instrument designed to measure the thermal plasma parameters. It consists of a retarding potential analyzer (RPA) used to determine total ion density $\left(N_{\mathrm{i}}\right)$, ion temperature $\left(T_{\mathrm{i}}\right)$, composition, and the ram ion velocity component and an ion drift meter (DM) to measure the cross-track ion velocity. The RPA can resolve the fractional composition of $\mathrm{H}^{+}, \mathrm{He}^{+}$, and $\mathrm{O}^{+}$in the ambient plasma and determines a single mean ion temperature for all species present. A detailed description of the functioning of the RPA and DM may be found in Heelis and Hanson (1998). Depending on instrument mode, the CINDI RPA measurements are made at either a 1 or a $2 \mathrm{~Hz}$ cadence, and the DM operates at $24 \mathrm{~Hz}$. This allows determination of the vector plasma motion at the RPA cadence. In order to ensure that only good quality ram velocity determinations were used for this study, a minimum ion density of $10^{3} \mathrm{~cm}^{-3}$ was required. In addition, since the least-squares analysis algorithm that produces the ram velocity produces the most accurate results in an environment that is a mixture of light ions $\left(\mathrm{H}^{+}\right.$and $\left.\mathrm{He}^{+}\right)$and $\mathrm{O}^{+}$, we required that the fractional composition of the ionosphere be between $40 \%$ and $90 \% \mathrm{O}^{+}$. Under these conditions the estimated accuracy of the RPA ram velocity is less than $10 \mathrm{~m} \mathrm{~s}^{-1}$ (decreasing with increasing plasma density), and the estimated accuracy of the cross-track measurement is $2 \mathrm{~m} \mathrm{~s}^{-1}$. For the purposes of this paper the plasma velocity measurements have been converted into a magnetic coordinate system. If $\boldsymbol{R}$ is the vector from the center of the Earth to the spacecraft, then the components are parallel to the geomagnetic field $\left(\boldsymbol{B}_{\mathrm{g}}\right)$, the zonal component, and the meridional component where the zonal component is in the $\boldsymbol{R} \times \boldsymbol{B}_{\mathrm{g}}$ direction (positive eastward) and the meridional component is in the zonal direction $\times \boldsymbol{B}_{\mathrm{g}}$ (positive upward).

The initial $402 \times 851 \mathrm{~km}$ altitude $13^{\circ}$ inclination orbit of C/NOFS undergoes precession in such a fashion that the spacecraft perigee samples all local times over the course of approximately 67 days. For the purposes of this paper we have averaged the data into bins according to date (1 month bin size), apex altitude ( $10 \mathrm{~km}$ bin size), longitude $\left(10^{\circ}\right.$ bin size), and SLT ( $1 \mathrm{~h}$ bin size). Along with the nominal $100 \%$ duty cycle of the spacecraft, this allows combining the bins in order to obtain statistical time and longitudinal pictures of all the measured parameters.

\section{Observations}

As previously stated, the first part of the C/NOFS mission covered a period of very low to moderate solar activity. Figure 1 presents the F10.7 radio flux measurements (used here as a proxy for solar extreme ultraviolet (EUV) flux) for January 2008 through December 2013. The black trace is the daily values, and the red diamonds are the monthly averages. The 2008-2009 period was extremely quiet with monthly averages generally below $80 \mathrm{sfu}\left(1 \mathrm{sfu}=10^{-22} \mathrm{~W} \mathrm{~m}^{-2} \mathrm{~Hz}^{-1}\right)$, while the 2010-2012 interval displayed moderate solar activity in the 100-150 sfu range. Particularly during the earlier interval, solar activity was well below levels under which topside ionospheric parameters have previously been measured in situ by satellites. As shown in Heelis et al. (2009), one result of this low solar activity is a general reduction in the altitude of the ionosphere and thermosphere, implying that C/NOFS is effectively operating further into the topside ionosphere than it would be under more typical conditions. 


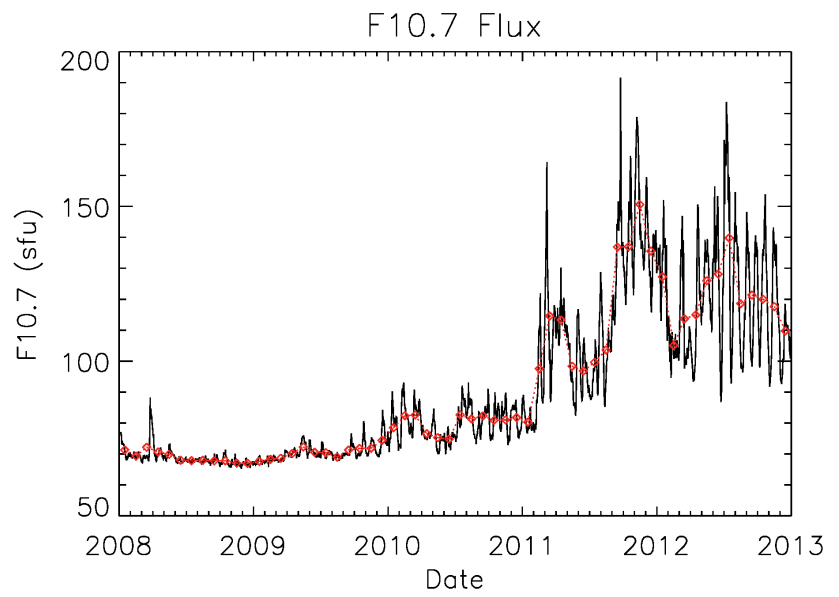

Fig. 1. Daily averaged F10.7 Flux versus date for January 2008December 2013 (black trace) and monthly averages (red diamonds).

We first examine the overall climatology of the lowlatitude topside zonal ion drifts averaged over 1-year periods beginning with the year 2012, a period of moderate solar activity that more closely resembles the conditions under which previous studies (e.g., Herrero and Mayr, 1986) have been conducted than the earlier years of the C/NOFS mission. Figure 2 shows a contour plot of the zonal ion velocity measured by CINDI as a function of longitude and solar local time using data from 2012 in the $400-1000 \mathrm{~km}$ apex altitude range. For this and all subsequent plots in this paper, a positive zonal drift value represents eastward flow and a negative value is westward. The monthly averaged F10.7 flux for this year was in the 100-140 sfu range. As might be expected from the previous work mentioned above, we see a pattern of westward drift during the day and eastward drift during the night. The morning change from eastward to westward occurs in the 04:00-05:00 SLT interval. This is consistent with the reversal times seen by Herrero and Mayr (1986) under similar levels of solar activity. The afternoon reversal back to eastward occurs at around 18:00-19:00 SLT, somewhat later than the 16:30-17:00 SLT reported by Herrero and Mayr (1986). We also see significant longitude variations in the afternoon and evening local times. The early evening exhibits an eastward peak that weakens in the $300-360^{\circ}$ longitude range, while around 16:00 SLT there are westward extrema near $30^{\circ}, 130^{\circ}$, and $310^{\circ}$. Indeed, the $300-360^{\circ}$ region has weaker eastward flow at night and stronger daytime westward flow than any other longitude sector. The standard deviations of the data are about $40 \mathrm{~m} \mathrm{~s}^{-1}$ during the day and $80 \mathrm{~m} \mathrm{~s}^{-1}$ at night reflecting the large geophysical variability of the drifts during this period of moderate solar activity.

The longitudinal structure can be examined in more detail in Fig. 3, which presents the SLT variation of the zonal drift every $20^{\circ}$ of longitude for the same 2012 data set used in Fig. 2. Each curve uses data averaged over the $10^{\circ}$ longitude interval indicated, and the mean value of the zonal

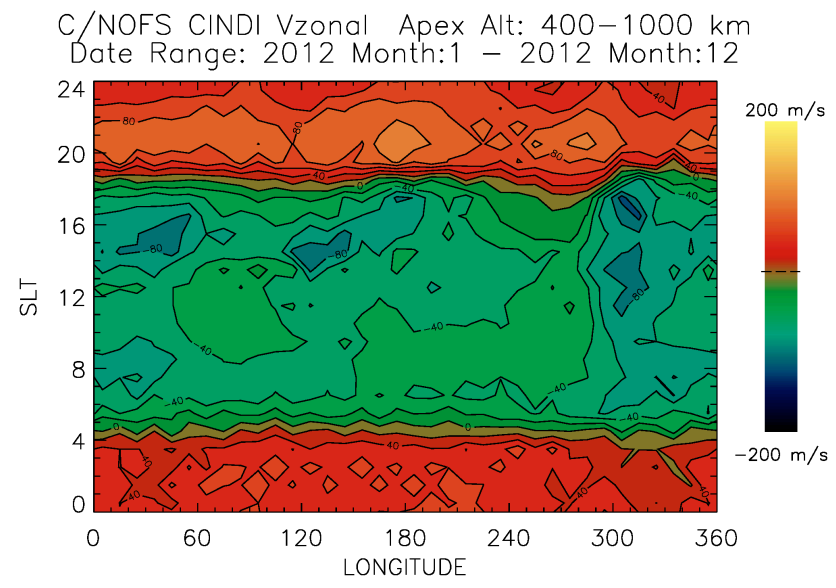

Fig. 2. Contour plot of CINDI zonal velocities versus SLT (hours) and longitude for the year 2012. All available data in the 400$1000 \mathrm{~km}$ apex altitude range were used. A positive value represents eastward drift.

drift is also given. Both the daytime westward flows and the pre-midnight eastward peak undergo longitude variations that lead to systematic changes in the net zonal drift. During the nighttime in the $0-290^{\circ}$ range, the pre-midnight peak stays in the range of $80-100 \mathrm{~m} \mathrm{~s}^{-1}$ reaching its maximum of $100 \mathrm{~m} \mathrm{~s}^{-1}$ at about $180^{\circ}$. In the $0-110^{\circ}$ longitude range, the daytime westward flow has two extrema: at about 07:00 and 16:00 SLT with a less westward peak at 12:00 SLT. From $120-180^{\circ}$ there is only one extremum in the westward drift, near 16:00 SLT. From $180^{\circ}$ to about $270^{\circ}$ the daytime flow becomes generally less westward and then becomes sharply more westward as the two-peak structure in the daytime appears. The net result of this is seen in the mean zonal flows with positive eastward motion (superrotation) occurring from about 55 to $295^{\circ}$ and westward motion (subrotation) occurring from $295^{\circ}$ back around to $55^{\circ}$. The minimum observed mean zonal drift is $-17.6 \mathrm{~m} \mathrm{~s}^{-1}$, seen in the $320-330^{\circ}$ longitude bin, and the maximum value of approximately $12.5 \mathrm{~m} \mathrm{~s}^{-1}$ in the $260-270^{\circ}$ range. Averaging over all values of longitude and SLT, we obtain a net eastward zonal drift of $2.91 \mathrm{~m} \mathrm{~s}^{-1}$.

Moving backwards in time, Figs. 4, 5, and 6 present, respectively, the zonal drift for 2011, 2010, and 2009 in the same format as Fig. 2. As can be seen from the F10.7 data in Fig. 1, solar activity decreases monotonically as one progresses from Fig. 2 to Figs. 4-6. The monthly F10.7 averages were in the $80-150$ sfu range for $2011,70-80$ sfu for 2010 , and near $70 \mathrm{sfu}$ for all of 2009. In comparison to 2012, the 2011 data in Fig. 4 show that the dayside zonal flow has intensified around midday at all longitudes, the drift reaching values less $-100 \mathrm{~m} \mathrm{~s}^{-1}$ in the $300-50^{\circ}$ and the $110^{\circ}$ longitude regions. The noontime westward flow is weakest near $280^{\circ}$ longitude. The 21:00 SLT eastward flow peak is weaker in 2011 than in 2012 at all longitudes, but is strongest at about 


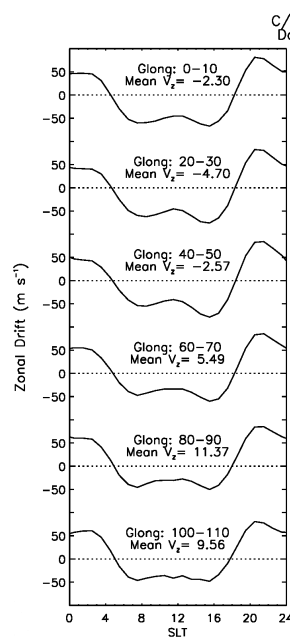

C/NOFS CINDI Vzonal Apex Alt: $400-1000 \mathrm{~km}$
Dote Range: 2012 Month:1 12012 Month: 12
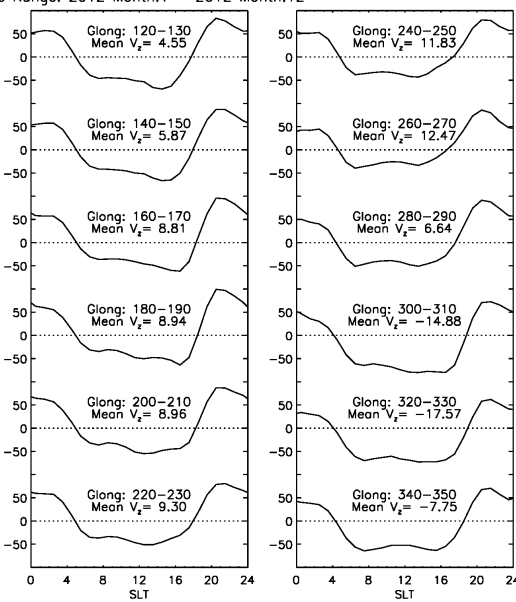

Fig. 3. Line plots of CINDI zonal ion drift versus SLT for selected longitudes during 2012 in the $400-1000 \mathrm{~km}$ apex altitude region (the same data set as Fig. 2). The mean zonal drift averaged over all $24 \mathrm{~h}$ of SLT is given for each longitude.

$50 \mathrm{~m} \mathrm{~s}^{-1}$ near $270^{\circ}$. There is a smaller morning-side eastward peak at 03:00 SLT and $190^{\circ}$ longitude. In Fig. 5 we see that in 2010 both the nighttime eastward and daytime westward flows are slightly weaker than in 2011 . The strongest eastward flow is centered on longitudes around $230-290^{\circ}$. The daytime westward flow is weakest in approximately the same longitude range. At other longitudes the predawn eastward flow is weaker and in some areas, notably $320-360^{\circ}$, actually turns eastward. Finally, Fig. 6 shows the zonal drift in 2009, a year with the lowest F10.7 fluxes that were consistently around $70 \mathrm{sfu}$. We only see limited areas of eastward flow in the pre-midnight region mostly in the $250-290^{\circ}$ and the $340-90^{\circ}$ areas. The dayside drifts are similar to 2010 , and are slightly less westward around $180-270^{\circ}$ and slightly more westward at $300-350^{\circ}$ longitude.

Examination of Figs. 2 and 4-6 indicate that there is a dependence of the zonal drift on solar activity as well as local time and longitude. Figure 7 presents a plot of the monthly averaged zonal drift versus the monthly averaged F10.7 flux for the August 2008-December 2012 time period. The data used were taken from the time frame of the pre-midnight peak in the eastward drift, 19:00-24:00 SLT. Data from all longitudes and the $400-1200 \mathrm{~km}$ apex altitude range were used. The plot indicates a positive correlation between F10.7 and the mean zonal velocity. The straight line indicates the least-squares fit to this data. The fit coefficients are shown in the lower right: the first coefficient gives the zero flux intercept as $-120 \mathrm{~m} \mathrm{~s}^{-1}$, and the second gives the slope as $1.53 \mathrm{~m} \mathrm{~s}^{-1} \mathrm{sfu}^{-1}$. The standard deviation of the data points is approximately $\pm 70 \mathrm{~m} \mathrm{~s}^{-1}$. Figure 8 is a similar plot for the 00:00-05:00 SLT interval (midnight-dawn). It also shows an only slightly less positive dependence of zonal drift on F10.7 with a best-fit slope of $1.41 \mathrm{~m} \mathrm{~s}^{-1} \mathrm{sfu}^{-1}$. In contrast,

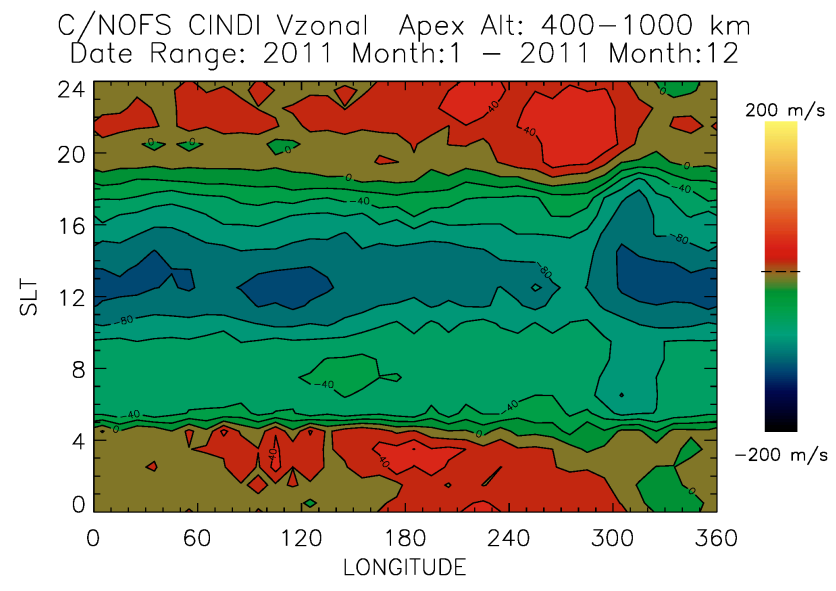

Fig. 4. Contour plot of CINDI zonal velocities versus SLT (hours) and longitude for the year 2011. All available data in the 400$1000 \mathrm{~km}$ apex altitude range were used.

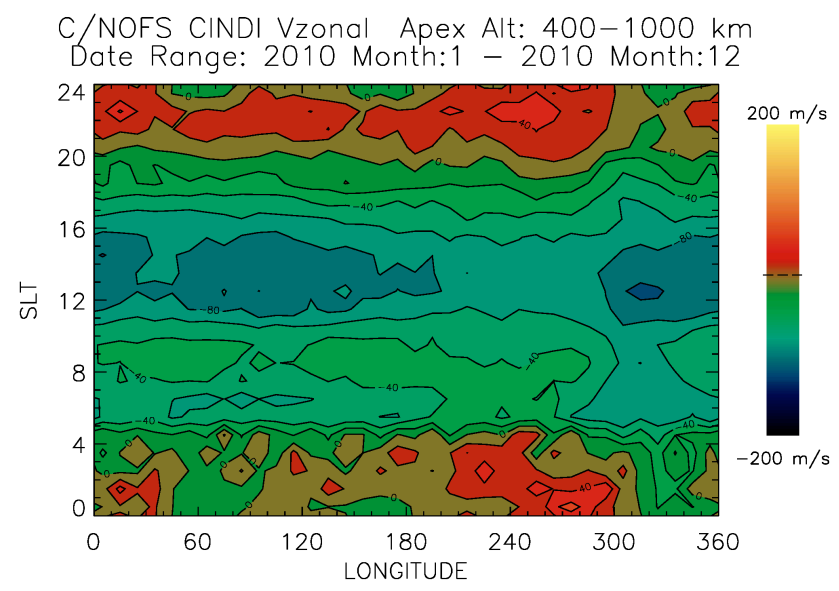

Fig. 5. Contour plot of CINDI zonal velocities versus SLT (hours) and longitude for the year 2010. All available data in the 400 $1000 \mathrm{~km}$ apex altitude range were used.

the daytime westward drift displays a much weaker dependence on solar activity as shown in Fig. 9. This plot uses data covering the 10:00-16:00 SLT interval. Almost all the data are westward, and the slope is only $0.50 \mathrm{~m} \mathrm{~s}^{-1} \mathrm{sfu}^{-1}$.

Another useful view of the data is obtained by looking at the SLT variation of the zonal drift over a limited longitude range for each of the four complete years of data used in this study. Figure 10 gives this plot for the $260-270^{\circ}$ longitude, a location where we see the highest value of the premidnight eastward flow in the moderate solar activity conditions of 2012. On the dayside we see that while westward flow is always present, there is less variation for the extremely low F10.7 conditions of 2009 with an average drift of around $-50 \mathrm{~m} \mathrm{~s}^{-1}$. For the solar active period of 2012, the daytime variation is also small with an average value of about $-30 \mathrm{~m} \mathrm{~s}^{-1}$. In the nighttime we see a consistent pattern with 


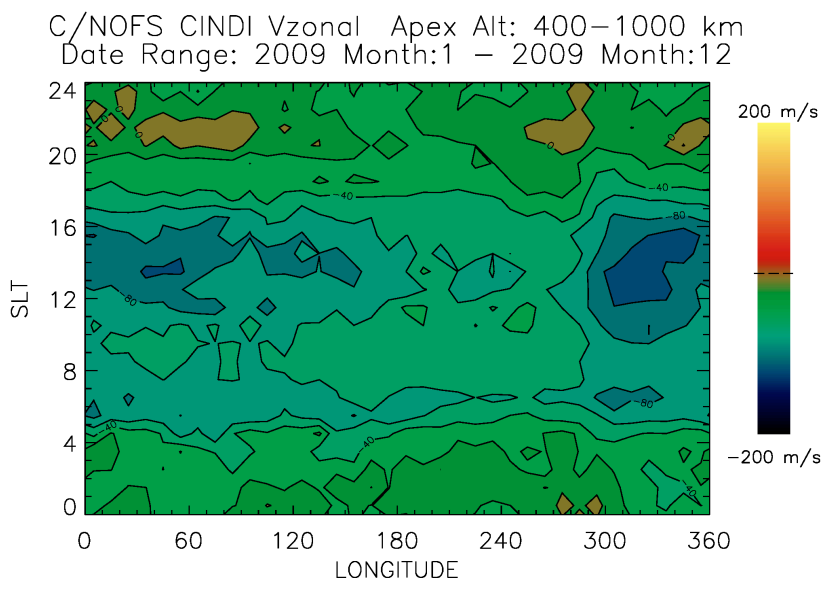

Fig. 6. Contour plot of CINDI zonal velocities versus SLT (hours) and longitude for the year 2009. All available data in the 400$1000 \mathrm{~km}$ apex altitude range were used.

a peak eastward flow at 21:00 SLT of approximately $0 \mathrm{~m} \mathrm{~s}^{-1}$ in 2009 increasing monotonically to $\sim 90 \mathrm{~m} \mathrm{~s}^{-1}$ in 2012 . In the post-midnight-dawn local time, there is less variation during the 2010-2012 period with drifts in the $20-40 \mathrm{~m} \mathrm{~s}^{-1}$ range with a drift of -10 to $-20 \mathrm{~m} \mathrm{~s}^{-1}$ in 2009 . The mean zonal drift averaged over the entire $24 \mathrm{~h}$ is listed and indicates that the net ionospheric motion is eastward (superrotation) only for 2012 and that the ionosphere subrotates at the lower levels of solar activity during the previous $3 \mathrm{yr}$.

Figure 11 presents the SLT variation of the zonal drift in the $170-180^{\circ}$ longitude range for 2012 for four different overlapping ranges of the apex altitude (magnetic latitude). Each range covers $400 \mathrm{~km}$ of apex altitude, and the altitude displayed on the plot is the base altitude of the associated range (i.e., the trace labeled $400 \mathrm{~km}$ covers $400-800 \mathrm{~km}$ altitude). Here we see that the net zonal drift is organized by apex altitude with the strongest eastward drift associated with the lowest apex altitude (lowest magnetic latitude) range. The average drifts get smaller and then reverse to become negative (westward) as the apex altitude increases.

\section{Discussion}

The ground-based measurements that are most easily compared to the CINDI data set come from the Jicamarca incoherent scatter radar (located at $11.9^{\circ} \mathrm{N}, 283.2^{\circ} \mathrm{E} ; 2^{\circ} \mathrm{N}$ magnetic dip latitude). An earlier comparison by Coley and Heelis (1989) between in situ eastward velocities from DE 2 and the Jicamarca radar found generally good agreement during the high solar activity period of 1981-1983. In that study the DE 2 measurements were made in the $200-600 \mathrm{~km}$ altitude range while the Jicamarca measurements were taken in the $300-400 \mathrm{~km}$ altitude range. The most comparable $\mathrm{Ji}$ camarca measurements to the CINDI data in this study were reported in Fejer et al. (2013) and cover the 2008-2011 date

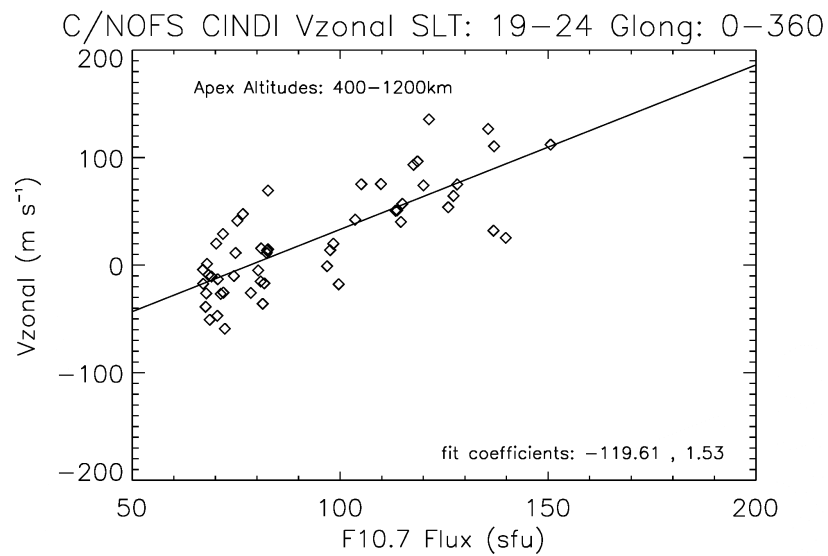

Fig. 7. Monthly averaged zonal drifts (diamonds) versus monthly averaged F10.7 flux for August 2008-December 2012. CINDI IVM data in the 19:00-24:00 SLT range, all longitudes, and the 400$1200 \mathrm{~km}$ apex altitude range were used. The least-squares fit straight line is shown, and the fit coefficients are indicated at the bottom right. See text for details.

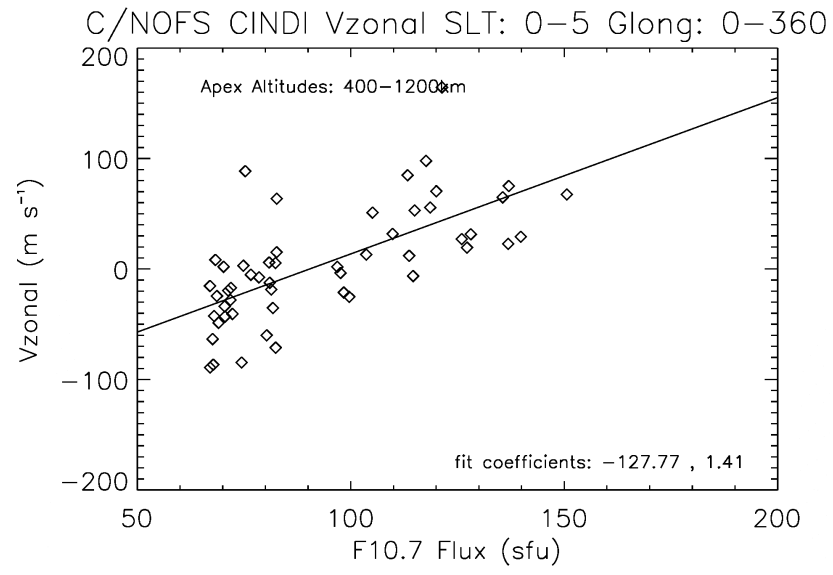

Fig. 8. Similar to Fig. 7 except for the 00:00-05:00 SLT range.

range. They give nighttime eastward peak velocities of about $120 \mathrm{~m} \mathrm{~s}^{-1}$ in the 21:00-23:00 SLT range, depending on the season. The maximum westward velocities of $40-80 \mathrm{~m} \mathrm{~s}^{-1}$ occur near noon. The corresponding 2012 CINDI measurements from the $280-290^{\circ}$ longitude range (see Fig. 3) have a maximum eastward velocity of $\sim 90 \mathrm{~m} \mathrm{~s}^{-1}$ at $21: 00$ SLT and double daytime westward velocity peaks of $\sim 50 \mathrm{~m} \mathrm{~s}^{-1}$ at 07:00 and 14:00 SLT. We note that the Jicamarca data set uses data from the low solar activity period of 2008-2009 where the CINDI data have a greatly reduced eastward nighttime peak as seen in Fig. 10. This difference can possibly be explained by the differing altitudes used by the two techniques. The daytime radar data were taken in the $200-600 \mathrm{~km}$ altitude range while the nighttime data were taken below $400 \mathrm{~km}$ (below the range of the C/NOFS orbit) due to the low nighttime densities and correspondingly lower signal to noise 


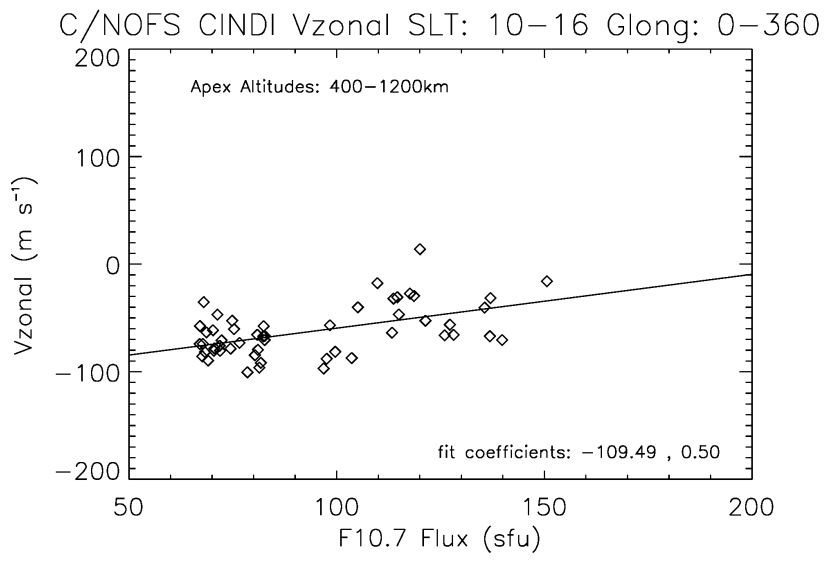

Fig. 9. Similar to Fig. 7 except for the 10:00-16:00 SLT range.

ratios during this time. As Fig. 11 demonstrates for the 2012 data, the magnitude of the nighttime peak depends on the apex altitude of the measurement, with lower apex altitudes (lower magnetic latitudes) having a more eastward flow. This would imply that Jicamarca might see more easterly zonal flow at night than CINDI.

VEFI data from C/NOFS are presented by Pfaff et al. (2010) and Fejer et al. (2013). These papers show data that have both similarities and differences to the results given in this paper. The zonal drifts derived from a limited amount of 2008 data in Pfaff et al. (2010) show a similar pattern to other studies but with a more limited range of $25 \mathrm{~m} \mathrm{~s}^{-1}$ westward in daytime to $50 \mathrm{~m} \mathrm{~s}^{-1}$ eastward at night. The more extensive VEFI data set used in Fejer et al. (2013) is binned so as to demonstrate seasonal variations of the zonal drift, but nevertheless shows great similarity to the data of Fig. 2, particularly in the general longitude variations. The drifts in the Jicamarca longitude sector are similar in magnitude and phase to those seen by CINDI.

An important factor here is that most previous measurements of topside zonal plasma drift have been made under moderate to active solar conditions as determined by standard EUV proxies. Since the level of solar activity under which C/NOFS has operated has varied from unusually low to moderate, this mission has provided an extension to the climatological database on the topside ionospheric region during conditions of an extremely contracted ionosphere (Heelis et al., 2009; Coley et al., 2010). This means that C/NOFS was effectively operating further above the primary altitudes of $\mathrm{E}$ and $\mathrm{F}$ region dynamo activity than other equatorial spacecraft and that the neutral winds responsible for the $\mathrm{F}$ region dynamo are generally well below the spacecraft altitude. The nighttime zonal flow as measured would then probably be driven by neutral winds at off-equatorial latitudes whose electric fields would map along magnetic field lines up to the region of C/NOFS. During the solar maximum period of 1999-2003, Pacheco et al. (2011) looked at magnetic

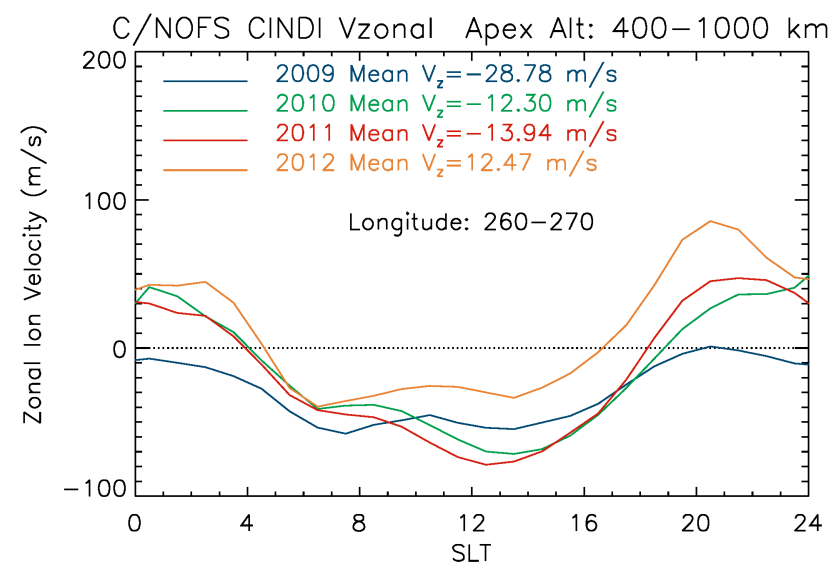

Fig. 10. CINDI zonal ion drift versus SLT in the 260-270 longitude range and the $400-100 \mathrm{~km}$ apex altitude range for each of the $4 \mathrm{yr}$ from 2009 to 2012 . The $24 \mathrm{~h}$ averaged zonal velocity is indicated for each year.

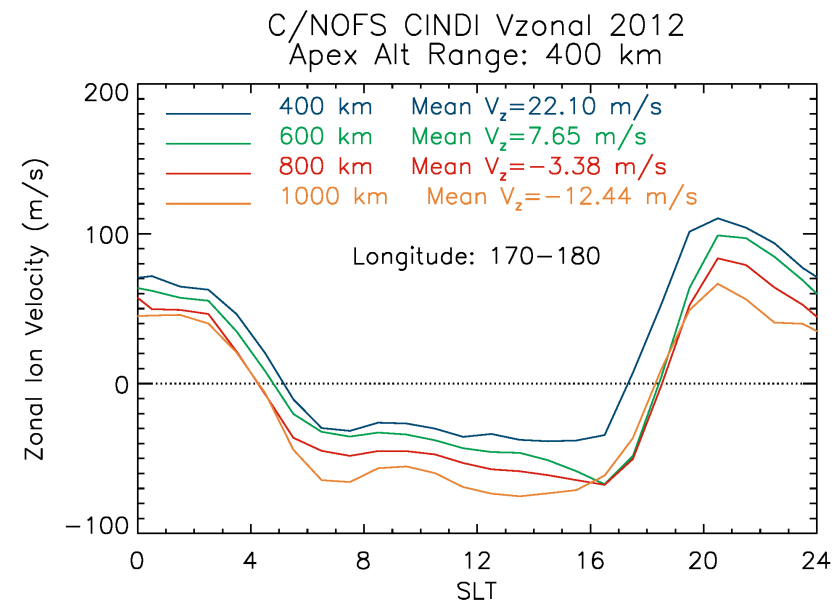

Fig. 11. CINDI zonal ion drift versus SLT in the $170-180^{\circ}$ longitude range for 2012 in four different apex altitude ranges. Each of the ranges begin at the lower bound indicated and extends upwards $400 \mathrm{~km}$.

latitude variations of zonal drifts using measurements from the ROCSAT-1 spacecraft. They find that the eastward peak decreases in magnitude with increasing magnetic latitude, while the daytime westward flow is relatively stable suggesting that the decrease of superrotation with latitude is mainly produced by neutral winds that also decrease with latitude. Given the weaker nature of the nighttime zonal plasma drifts in the 2008-2009 period, it is reasonable to assume that the $F$ region dynamo is also weaker during this period in the off-equatorial latitudes. This view is supported by Huang et al. (2012), who find a correlation between VEFI zonal drifts and GRACE neutral densities and suggest that the zonal ion drifts may be used as a proxy for neutral wind measurements. 


\section{Summary}

Measurements of the low-latitude topside zonal ion drift were made by the CINDI instrument on board the C/NOFS spacecraft during the 2009-2012 time interval, a period of very low to moderate solar activity as determined from F10.7 $\mathrm{cm}$ radio fluxes. The drifts observed under moderate solar activity in the $280^{\circ}$ longitude region are organized into a diurnal pattern that closely resembles the drifts seen previously by the Jicamarca incoherent scatter radar. There are clear longitude variations with smaller nighttime eastward drifts at longitudes away from the American sector. The pre-midnight drifts show a definite F10.7 dependence, while the daytime drifts show relatively little variation with solar activity. The apex altitude (magnetic latitude) variation of the drifts indicates a more westerly flow at higher altitudes. The decrease in the nighttime eastward ion flow with lower solar activity and altitude seems to indicate reduced $\mathrm{F}$ region zonal neutral winds that are in turn producing a considerably weakened F region dynamo during the 2009-2010 period.

Acknowledgements. The C/NOFS mission is supported by the Air Force Research Laboratory, the Department of Defense Space Test Program, the National Aeronautics and Space Administration (NASA), the Naval Research Laboratory, and the Aerospace Corporation. This research was supported by the National Aeronautics and Space Administration under contracts NAS5-01068 and NNX10AT02G. F10.7 data were provided by the NOAA Space Weather Prediction Center.

Topical Editor K. Hosokawa thanks two anonymous referees for their help in evaluating this paper.

\section{References}

Coley, W. R. and Heelis, R. A.: Low-latitude zonal and vertical ion drifts seen by DE 2, J. Geophys. Res., 94, 6751-6761, 1989.

Coley, W. R., Heelis, R. A., and Spencer, N. W.: Comparison of lowlatitude ion and neutral zonal drifts using DE 2 data, J. Geophys. Res., 99, 341-348, 1994.

Coley, W. R., Heelis, R. A., Hairston, M. R., Earle, G. D., Perdue, M. D., Power, R. A., Harmon, L. L., Holt, B. J., and Lippincott C. R.: Ion temperature and density relationships measured by CINDI from the C/NOFS spacecraft during solar minimum, J. Geophys. Res., 115, A02313, doi:10.1029/2009JA014665, 2010.

Fejer, B. G.: Low latitude ionospheric electrodynamics, Space Sci. Rev., 158, 145-166, doi:10.1007/s11214-010-9690-7, 2011.

Fejer, B. G., Gonzales, C. A., Farley, D. T., Kelley, M. C., and Woodman, R. F.: Equatorial electric fields during magnetically disturbed conditions, 1 , The effect of the interplanetary magnetic field, J. Geophys. Res., 84, 5797-5802, 1979a.

Fejer, B. G., Farley, D. T., Woodman, R. F., and Calderon C.: Dependence of equatorial $F$ region vertical drifts on season and solar cycle, J. Geophys. Res., 84, 5792-5796, 1979 b.

Fejer, B. G., Farley, D. T., Gonzales, C. A., Woodman, R. F., and Calderon, C.: F region east-west drifts at Jicamarca, J. Geophys. Res., 86, 215, 1981.

Fejer, B. G., Kudeki, E., and Farley, D. T.: Equatorial F region zonal plasma drifts, J. Geophys. Res., 90, 12249-12255, 1985.
Fejer, B. G., de Paula, E. R., Gonzalez, S. A., and Woodman, R. F.: Average vertical and zonal F region plasma drifts over Jicamarca, J. Geophys. Res., 96, 13901-13906, doi:10.1029/91JA01171, 1991.

Fejer, B. G., Tracy, B. D., and Pfaff, R. F.: Equatorial zonal plasma drifts measured by the C/NOFS satellite during the 2008-2011 solar minimum, J. Geophys. Res. Space Phys., 118, 3891-3897, doi:10.1002/jgra.50382, 2013.

Hartman, W. A. and Heelis, R. A.: Longitudinal variations in the equatorial vertical drift in the topside ionosphere, J. Geophys. Res., 112, A03305, doi:10.1029/2006JA011773, 2007.

Heelis, R. A.: Electrodynamics in the low and middle latitude ionosphere: a tutorial, J. Atmos. Sol.-Terr. Phys., 66, 825-838, 2004.

Heelis, R. A. and Hanson, W. B.: Measurements of thermal ion drift velocity and temperature using planar sensors, in: Measurement Techniques in Space Plasmas: Particles, Geophys. Monogr. Ser., Vol. 102, edited by: Pfaff, R. F., Borovsky, J. E., and Young, D. T., 61-71, AGU, Washington, D. C., 1998.

Heelis, R. A., Kendall, P. C., Moffett, R. J., and Windle, D. W. Electrical coupling of the $\mathrm{E}$ and $\mathrm{F}$ regions and its effect on $\mathrm{F}$ region drifts and winds, Planet Space Sci., 22, 743-756, 1974.

Heelis, R. A., Earle, G., Coley, R., Power, B., Perdue, M., Hairston, M., Lippincott, R., Harmon, L., and Holt, B.: Behavior of the $\mathrm{O}+/ \mathrm{H}+$ transition height during the extreme solar minimum of 2008, Geophys. Res. Lett., 36, L00C03, doi:10.1029/2009GL038652, 2009.

Herrero, F. R. and Mayr, H. G.: Tidal decomposition of zonal neutral and ion flows in the Earth's upper equatorial thermosphere, Geophys. Res. Lett., 13, 359-362, 1986.

Huang, C.-S., Rich, F. J., de La Beaujardiere, O., and Heelis, R. A.: Longitudinal and seasonal variations of the equatorial ionospheric ion density and eastward drift velocity in the dusk sector, J. Geophys. Res., 115, A02305, doi:10.1029/2009JA014503, 2010.

Huang, C. Y., Roddy, P. A., Sutton, E. K., Stoneback, R., Pfaff, R. F., Gentile, L. C., and Delay, S. H.: Ion-neutral coupling during deep solar minimum, J. Atmos. Sol.-Terr. Phys. doi:10.1016/j.jastp.2012.11.009, 2012.

Maynard, N. C., Aggson, T. L., Herrero, F. A., and Liebrecht, M. C.: Average low-latitude meridional electric fields from DE 2 during solar maximum, J. Geophys. Res., 93, 4021-4037, 1988.

Maynard, N. C., Aggson, T. L., Herrero, F. A., Liebrecht, M. C., and Saba, J. L.: Average equatorial zonal and vertical ion drifts determined from San Marco DC electric field measurements, J. Geophys. Res., 100, 17465-17479, doi:10.1029/95JA00767, 1995.

Pacheco, E. E., Heelis, R. A., and Su, S.-Y.: Superrotation of the ionosphere and quiet time zonal ion drifts at low and middle latitudes observed by Republic of China Satellite-1 (ROCSAT-1), J. Geophys. Res., 116, A11329, doi:10.1029/2011JA016786, 2011.

Pfaff, R., Rowland, D., Freudenreich, H., Bromund, K., Le, G., Acuña, M., Klenzing, J., Liebrecht, C., Martin, S., Burke, W. J., Maynard, N. C., Hunton, D. E., Roddy, P. A., Ballenthin, J. O., and Wilson, G. R.: Observations of DC electric fields in the lowlatitude ionosphere and their variations with local time, longitude, and plasma density during extreme solar minimum, J. Geophys. Res., 115, A12324, doi:10.1029/2010JA016023, 2010.

Woodman, R. F.: East-west ionospheric drifts at the magnetic equator, Space Res., 12, 969, 1972. 